\title{
Psychogeriatric training for senior registrars in geriatric medicine
}

\author{
DunCan R. Forsyth, Consultant Geriatrician, Addenbrooke's Hospital, \\ Hills Road, Cambridge CB2 2QQ
}

Since the late 1960s the number of psychiatrists choosing to specialise in old age psychiatry has increased dramatically (Wattis, 1988) and in 1989 the Royal College of Psychiatrists recognised the specialty's status. Recent recommendations of the Royal Colleges of Physicians and Psychiatrists (Report of a Joint Working Party of the Royal Colleges, 1989) have considerable implications for the continued development of cooperation between psychogeriatricians and geriatricians and for senior registrar (SR) training in both specialties. This study attempts to describe the availability of and attitudes towards training in psychogeriatrics (PG) of geriatric SRs.

\section{The study}

Postal questionnaires were sent to 162 SRs identified from the British Geriatrics Society (BGS) trainee mailing list. The questionnaire was phrased in a pragmatic form and contained space for additional comments. Replies were made anonymously.

\section{Findings}

One hundred and four replies were received, a response rate of $64 \%$. Eighty-eight $(85 \%)$ had some PG training, $15(14 \%)$ had none and other commitments always prevented one attending a joint liaison meeting. Secondment was expected in three regions (Mersey, West Midlands and Wessex) and one district (Nottingham), the arrangements for this being left to the individual SR. Elsewhere arrangements varied enormously both within and between regions, from formal secondments of 2-26 weeks; weekly joint service meetings; full or half day release; ad hoc liaison; to no opportunities at all. Where available, PG training was rarely continuous throughout the SR's appointment. Several had instigated PG liaison where it had not previously existed, or had increased existing links. On-call commitments to geriatrics were generally continued during these attachments.

Fifty-seven $(55 \%)$ were dissatisfied with their PG training. Comments regarding improvements in training and the feasibility of secondments overlapped.
All but one considered PG to be an important part of their training. Many considered it 'essential' or 'vital' as in many districts much of this work is performed by geriatricians, and where there were psychogeriatricians better knowledge of each other's specialty should facilitate mutual cooperation. Other reasons given included the difficulty of diagnosing depression $v$. dementia in the elderly; the need to revise their ability to do a mental state examination as well as developing additional expertise and experience. All respondents considered PG liaison would be part of their consultant duties. Several commented that where formal liaison was constrained by geography, manpower or time good working relationships were essential.

Twenty-six ( $25 \%)$ considered secondment impractical as colleagues would find the strain of taking on their service commitments too great, hence their consultants were reluctant to release them. Many of the $68(65 \%)$ who considered secondment feasible, if carefully planned, also saw supernumerary status as a prerequisite. Some believed that continuing to provide emergency cover in their own specialties would enable colleagues to manage the routine service commitments during a short-term secondment. A minority were not in favour of secondment as it would interfere with their research and teaching commitments. Three considered secondments irrelevant and an inappropriate way to gain PG experience. Two thought it more important that psychiatry SRs gained experience in geriatrics than vice-versa.

It was emphasised that the period required for training purposes should be clearly defined and training requirements standardised. The SR should neither be an inactive 'watch-dog' nor be expected to provide a service commitment. As standards of geriatric and PG practice vary within and between regions, secondments should offer the opportunity to gain experience of services not found in that district/ region. Several suggested that it may even be more beneficial to visit a centre of renown than accept secondment in their own district.

Suggestions ranged from one to six months as the most appropriate period of time for secondment, although some argued that a planned sessional programme was a more appropriate learning forum. 
There was general agreement that either arrangement should be an integral part of the SR's time-table. It was noted that it would be easier to accommodate the lesser numbers of PG SRs. Many advocated joint assessment units to facilitate the longer-term training needs of both groups. Development of joint academic meetings was also suggested.

Of the 15 SRs with no experience of PG, nine did not identify any reason for this. The following local barriers were identified: no psychogeriatrician in their district (15); service commitments and colleagues being overstretched (14); poor liaison between the respective units (7); paucity of recognised trainers (5); geographical separation of the two units (4); PG training not encouraged (2); and the greater number of geriatric SRs compared to PG SRs (2).

\section{Comment}

The response rate of $64 \%$ is similar to that of a previous survey based on the BGS trainee mailing list (Knight, 1986). The true reply rate is likely to be much higher due to posts being vacant as a result of the incumbent not yet being replaced after promotion or being absent on sabbatical. The views expressed, therefore, are likely to be more representative of the SR population.

The importance placed on liaison with colleagues in old age psychiatry is in keeping with the guidelines of the BGS and the College (Kaufmann \& Bates, 1990). Experience in PG is more widely available now than in $1983(85 \%$ v. $65 \%)$, yet there is more dissatisfaction with it $(55 \%$ v. $38 \%)$ and there are more without (14\% v. $9 \%$ ) experience in PG (Alistair Ritch, personal communication). Training currently available in PG varies enormously throughout the country; if its availability and acceptability is to improve, the large numbers of geriatric SRs will necessitate an increase in the number of recognised trainers. Any improvements in training or in the continued liaison and educational roles between the specialties would be welcome. The success of future more formalised reciprocal training (Report of a Joint Working Party of the Royal Colleges, 1989) does, however, depend on the supernumerary status of SRs. Although only $25 \%$ considered secondments impractical for this reason, many others thought them feasible only if SRs were supernumerary. Suggestions of cross-boundary flow to centres of renown have obvious practical difficulties related to numbers and geography.

In the majority of instances, liaison between geriatric and PG services was a one-way affair from the geriatric unit. Two instances were found of psychiatry SRs attending joint education meetings. In Nottingham the psychiatry SR has one to two sessions a week in geriatrics and in Wessex a two month secondment has recently been introduced. The West Midlands are introducing four joint sessions for the PG SRs into the geriatric SRs' training programme and also hope to arrange formal attachment of SRs to each others' units.

The many vacant psychogeriatrician posts (Watson \& Jolley, 1989) imply that for some time to come geriatricians will have a high PG workload. Proper PG training is, therefore, essential for geriatric SRs. This should not undermine the continued concerted efforts towards the appointment of adequate numbers of psychogeriatricians. There is both clinical and political necessity for greater collaboration between geriatric and PG units. The development of joint assessment units, as recommended in $\mathrm{HM}(70) 11$, would facilitate the training of SRs in each others' specialities and, hopefully, improve the poor relationships that still exist in some districts (Kaufmann \& Bates, 1990).

Geriatric SRs have expressed reservations regarding the implementation of a programme of reciprocal training. A similar survey of the SR group of the Royal College of Psychiatrists should be undertaken.

\section{References}

Report of a Joint Working Party of the Royal Colleges of Physicians and of Psychiatrists: Specialist services and medical training for the care of elderly people with mental illness (1989) London: Royal College of Psychiatrists.

KaufmanN, B. M. \& Bates, A. B. (1990) Factors affecting provision of psychogeriatric care: a survey of geriatricians' views. Care of the Elderly, 2, 25-27.

KNIGHT, P. V. (1986) Senior registrar's views on geriatric medicine. Journal of the Royal College of Physicians of London, 20, 271-272.

Watson, J. P. \& Jolley, D. J. (1989) A survey into the availability of higher specialist training in the psychiatry of old age in England and Wales 1983-88 and the yield of consultants from the training scheme. Psychiatric Bulletin, 13, 514-524.

WATTIS, J. P. (1988) Geographical variations in the provision of psychiatric services for old people. Age and Ageing, 17, 171-180. 